LBL-20479

\section{EFFECTS OF SILICA REDISTRIBUTION ON PERFORMANCE \\ OF HIGH-LEVEL NUCLEAR WASTE REPOSITORIES \\ IN SATURATED GEOLOGIC FORMATIONS}

LBL -20479

4. Verma and K. Pruess

TI87 000125

Earth Sciences Division

Lawrence Berkeley Laboratory

University of California

Berkeley, California 94720

November 1985

Prepared for

Waste Management Branch

Division of Radiation Programs and Earth Sciences

Office of Nuclear Regulatory Research

U.S. Nuclear Regulatory Commission

Washington, D.C. 20555

This work was supported by the U.S. Nuclear Regulatory Commission. through NRC Fin No. B30-16-3 under Interagency Agreements DOE-60-83-388 and 60-8:3-367, through [:.S. Department of Energy Contract No. DE-AC03-76SF00098. 


\section{ABSTRACT}

Evaluation of the thermohydrological conditions near high-level nuclear waste packages is needed for the design of the waste canister and for overall repository design and performance assessment. Most available studies in this area have assumed that the hydrologic properties of the host rock do not change in response to the thermal, mechanical or chemical effects caused by waste emplacement. However, the ramifications of this simplifying assumption have not been substantiated.

We have studied dissolution and precipitation of silica in thermally diriven flow systems, including changes in formation porosity and permeability. Using numerical simulation, we compare predictions of thermohydrological conditions with and without inclusion of silica redistribution effects. Two cases were studied, namely, a canister-scale problem, and a repository-wide thermal convection problem, and different pore models were employed for the permeable medium (fractures with uniform or non-uniform cross sections). We find that silica redistribution generally has insignificant effects on host rock and canister temperatures, pore pressures, or flow velocites. 


\section{INTRODUCTION}

Emplacement of high-level nuclear wastes in water-saturated rock formations will give rise to the development of a hydrothermal convection system, in which fluid flow is driven by buoyancy forces. Fluid convection is expected to persist for thousands of years because of the slow decay of actinides in the nuclear waste and the low thermal conductivity of formation rocks. Over and above the natural convection flow, there is a unidirectional flow of the formation water from a cooler region towards hotter pressure sinks created by the storage tunnel and canister holes, until they are saturated and pressure equilibrates $(\sim 100$ years $)$.

A quantitative understanding of these thermo-hydrologic flows is crucial for design and performance assessment of a nuclear waste repository. This paper studies the impact of silica redistribution in non-isothermal flow fields on performance of a nuclear waste repository situated in a saturated geologic formation. A study of a similar problem for the partially saturated tuff formations at the Nevada Test site was recently undertaken by Braithwaite and Nimick (1984).

The solubility of silica in subcritical conditions depends primarily on temperature. Groundwater flowing towards regions of higher temperature is deficient in silica, and will dissolve silica-containing rock minerals along the flow path. Conversely, water flowing towards cooler regions will generally be supersaturated and silica precipitation will take place along the flow path. In the context of nuclear waste isolation, it is nct the redistribution of silica-as such which is of concern, but its potential impact on the transport of heat, fluid, and chemical constituents. (Possible effects on the mechanical properties of the rock were not considered in the present study.) The hydrologic impacts of silica redistribution are brought about by changes in formation porosity and permeability from 
silica dissolution or precipitation. Strong effects of silica redistribution on rock porosity and permeability have been observed in laboratory experiments (Morrow et al., 1981; Moore et al., 1981; Keith et al., 1983; Vaughan, 1985).

The porosity changes can be easily related to precipitated or dissolved mass, but the permeability change associated with this change in porosity is a much more complex problem, as the porosity-permeability correlations depend on many geometric factors such as: pore-size distribution, pore shapes, and connectivity. Since there is a wide variation in these geometric properties among natural rock formations, the porositypermeability correlations will generally depend on the rock type and will be site specific. We have derived several correlations for different pore shape and size distributions in idealized permeable media, which are believed to capture essential features of real systems.

In the present study we have considered both a room scale problem which was previously considered, without including silica redistribution effects, by Pruess and Bodvarsson, (1982), and a repository scale problem. Under suitable approximations, these models were converted to two-dimensional axisymmetric models and coupled thermal, hydraulic, and chemical flow fieldis were simulated numerically. The results indicate that the effects of silica redistribution on the canister and the host rock temperatures, formation porosity, and flow velocity, are generally insignificant. The only apprecıable impact of silica redistribution was on permeability enhancement of the formation rock in the immediate vicinity of the canister hole. This phenomenon results in increased flux of formation water (by up to $30 \%$ over the reference case) in to the storage room and the canister hole. 


\section{MODELING APPROACH}

\section{Numerical Scheme}

The simulations presented in this study were carried out with the aid of the numerical code MULKOM (Pruess, 1983), which was developed at Lawrence Berkeley Laboratory for modeling of multi-phase, multi-component fluid and heat flow in porous and fractured media. The version of MULKOM used here accounts for water in liquid and vapor form and for dissolved as well as for solid silica, the latter being represented as quartz polymorph. All phases and the rock formations are assumed to be in local thermal equilibrium. Our code has the capability to handle finite rates of quartz dissolution and precipitation (i.e., kinetics), but in the simulations reported below we have assumed that dissolved silica concentrations correspond to equilibrium quartz solubilities, as given by Fournier and Potter (1982). Assuming instantaneous local equilibrium for dissolved silica will provide a conservative (upper) limit on the amount of material dissolved or precipitated in a certain rock volume per unit time. This, in turn, will provide a conservative estimate on expected porosity and permeability changes, and on overall thermohydrologic impact of silica redistribution.

The mass balance equations for water and silica, and the energy balance equation can all be written in the following general form:

$$
\frac{d}{d t} \int_{V_{n}} M^{(k)} d V=\int_{\sigma_{n}} F^{(k)} \cdot n d \sigma+\int_{V_{b}} Q^{(k)} d V
$$

The accumulation terms are written as follows:

$$
\begin{array}{ll}
\text { water }(\mathrm{k}=1): & \mathrm{M}^{(1)}=\phi\left(\mathrm{S}_{l} \rho_{l}+\mathrm{S}_{\mathrm{v}} \rho_{\mathrm{v}}\right) \\
\text { silica }(\mathrm{k}=2): & \mathrm{M}^{(2)}=\tilde{\phi} \mathrm{S}_{\mathrm{s}} \rho_{\mathrm{s}}+\phi\left(\mathrm{S}_{l} \rho_{l} \mathrm{X}_{l}^{(2)}+\mathrm{S}_{\mathrm{v}} \rho_{\mathrm{v}} \mathrm{X}_{\mathrm{v}}^{(2)}\right) \\
\text { heat }(\mathrm{k}=3): & \mathrm{M}^{(3)}=\left[(1-\tilde{\phi}) \rho_{\mathrm{r}} \mathrm{C}_{\mathrm{r}}+\tilde{\phi} \mathrm{S}_{\mathrm{s}} \rho_{\mathrm{s}} \mathrm{C}_{\mathrm{s}}\right] \mathrm{T}+\phi\left(\mathrm{S}_{l} \rho_{l} \mathrm{u}_{l}+\mathrm{S}_{\mathrm{v}} \rho_{\mathrm{v}} \mathrm{u}_{\mathrm{v}}\right)
\end{array}
$$


Here $\bar{\phi}$ is the gross porosity for unit formation volume, comprising the "active" porosity $\phi$ and the volume of solid silica (quartz). "Active" porosity represents the void volume, per unit formation volume, available to the fluid phases. This term will subsequently be referred to as "porosity" to be consistent with traditional nomenclature. $\mathrm{S}_{\mathrm{s}}$ denotes the fraction of volume in $\tilde{\phi}$ occupied by quartz. We have the following relationship between active porosity and quartz volume fraction:

$$
\phi=\tilde{\phi}\left(1-S_{s}\right)
$$

Thus dissolution or precipitation of quartz (changes in $\mathrm{S}_{\mathrm{s}}$ ) will produce changes in porosity $\phi$, which in turn will change formation permeability, $\mathrm{k} . \rho_{l}, \rho_{\mathrm{v}}, \rho_{\mathrm{s}}$, and $\rho_{\mathrm{r}}$ are the densities of liquid, vapor, quartz, and formation rock phases, respectively. $C_{s}$ and $C_{r}$ are quartz and rock specific heats, and $u_{l}, u_{v}$ are specific internal energies of liquid and vapor. $X_{l}^{(2)}$ and $X_{v}^{(2)}$ are the mass fractions of dissolved silica in liquid and vapor phases. The expressions for mass flux of water and heat flux are identical to those used by Pruess and Narasimhan (1985), and need not be repeated here. Mass flux of dissolved silica is expressed in terms of liquid and vapor phase fluxes as

$$
F^{(2)}=F_{l} X_{l}^{(2)}+F_{v} X_{v}^{(2)}
$$

Thermophysical properties of liquid water and vapor were computed from the equation of state formulation given by Haar et al. (1979), with the exception of viscosity which was obtained from the correlation provided by the International Formulation Committee (1967). The densities of water and silica were assumed additive, i.e., the volume of water or vapor containing dissolved silica was assumed equal to the volume of pure water or vapor at the same conditions of pressure and temperature.

The governing equations az given above are highly non-linear and strongly coupled due to variable fluid properties, relative permeabilities, phase transformation effects, and the dependence of permeability upon porosity. The equations are discretized in space with the integral finite difference method. using first order forward finite differences in 
time. All Hux terms are handled fully implicitly, and are $100 \%$ upstream weighted. The resulting set of coupled non-linear algebraic equations is solved by means of NewtonRaphson iteration. The linear equations obtained at each iteration step are solved with a sparse version of LU-decomposition (Duff, 1977). 


\section{POROSITY-PERMEABILITY RELATIONSHIP}

The porosity-permeability relationships used in this study were derived from a highly idealized model of permeable media shown schematically in Figure 1 . The permeable medium is assumed to have a set of non-intersecting planar flow channels with in general non-uniform cross-sectional area. Under suitable approximations (Verma and Pruess, 1986), the permeability and porosity are correlated by

$$
\frac{\mathrm{k}}{\mathrm{k}_{\mathrm{o}}}=\theta^{3} \frac{1-\Gamma+\Gamma / \nu^{3}}{1-\Gamma+\Gamma\left(\frac{\theta}{\theta+\nu-1}\right)^{3}}
$$

where $\Gamma$ is the fraction of flow-channel length with aperture $\tilde{b}$ (Fig. 1), $\nu$ represents the area ratio, $\left(\nu \equiv \frac{\check{\mathrm{b}}}{\mathrm{b}}\right)$, and $\theta$ is normalized porosity given by

$$
\theta=\frac{\phi-\phi_{\mathrm{c}}}{\phi_{\mathrm{o}}-\phi_{\mathrm{c}}}
$$

$\phi_{\mathrm{c}}$ is the critical porcsity defined as the smallest value to which porosity can be reduced by silica scaling on the flow channel wall. Permeability of the matrix reduces to zero at this porosity. Critical porcsity is correlated to the geometric factors by

$$
\phi_{c}=\Gamma(\bar{b}-b)
$$

In the current study we have used three different porosity-permeability relationships namely, simple cubic (i.e., all the flow channels are identicil in aperture and have uniform area of cross section, $\phi_{c}=0$ ), series (Fig. 1) with $\phi_{c}=0.8$, and series with $\phi_{c}=0.95$. The latter case was chosen to explore effects of an extremely strong dependence of permeability upon porosity changes. These relationships over a limited range are shown in Figure 2. Note that the change in slope at $\phi / \phi_{0}=1$ is due to a change in horizontal scale at this point. 


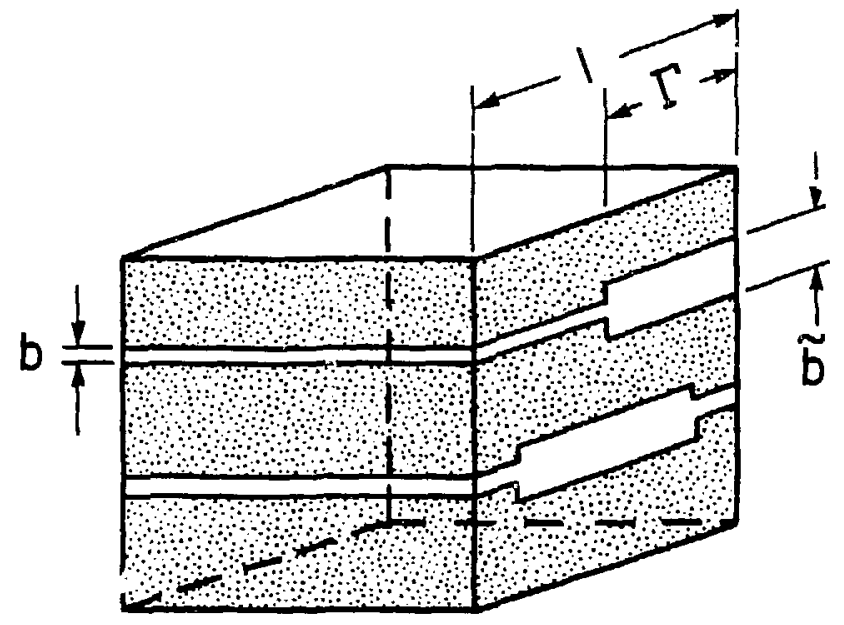

Figure 1. Idealized model of permeable media. 


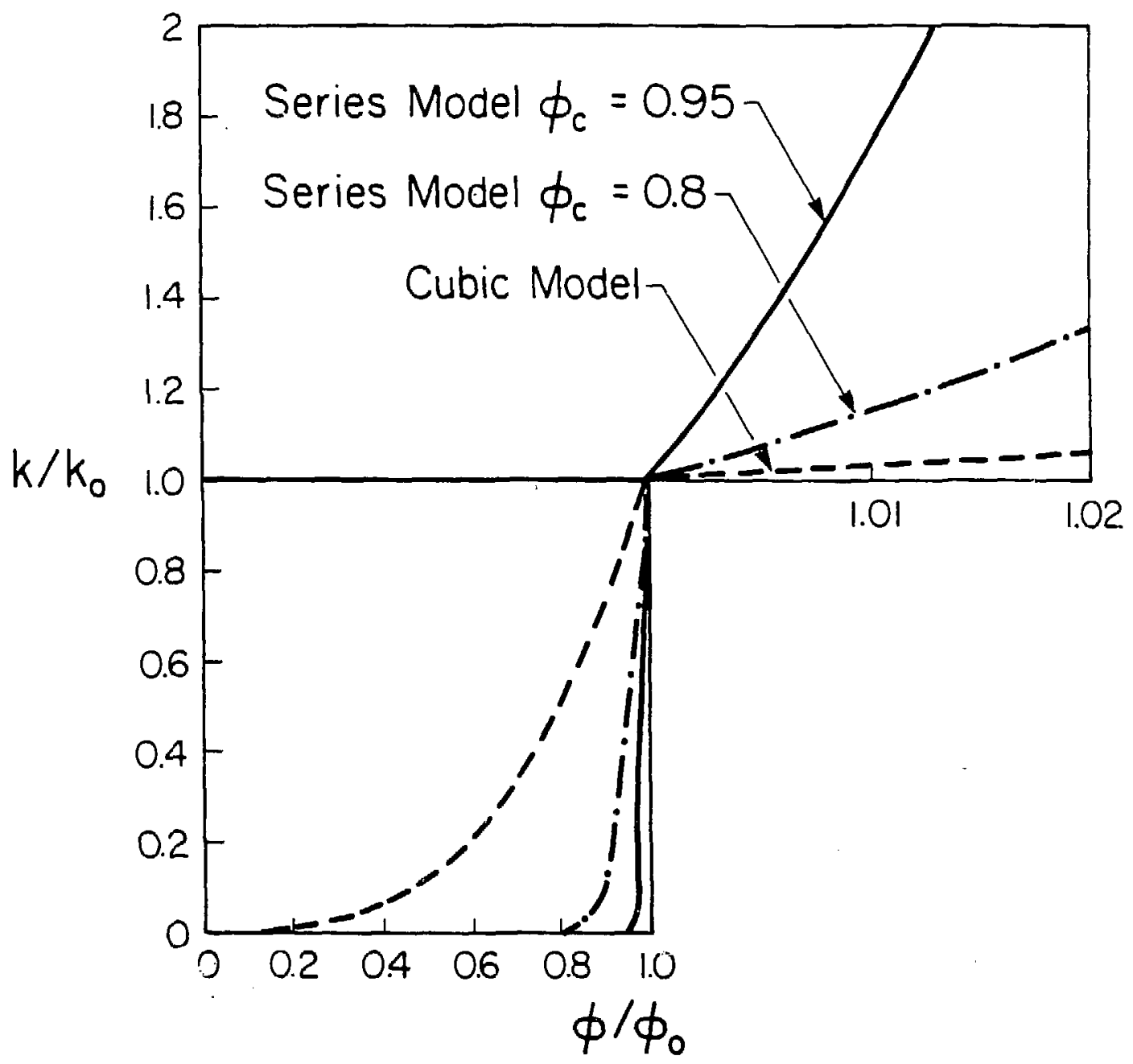

XBL $859-10761$

Figure 2. Porosity-permeability relationships for three different models considered in this study. 


\section{CASES STUDIED}

We have evaluated silica redistribution effects for a room-scale model previously studied by Pruess and Bodvarsson (1982), and for a repository-scale model.

\section{Room-Scale Model}

This model represents a 2-D axisymmetric approximation for a symmetry element of a reference repository design from the BWIP project. The approximations and assumptions behind this model have been discussed in detail in a report by Pruess and Bodvarsson (1982), to which the interested reader is referred. The geometric approximation used for modeling the flow system is shown in Figure 3. A linear string of 8.5 waste packages is placed at the axis of a cylinder of $19.89 \mathrm{~m}$ radius, at the mantle of which ambient boundary conditions of $\mathrm{T}=57.3^{\circ} \mathrm{C}$ and $\mathrm{p}=130$ bars are maintained. The hole containing the waste packages is connezted to a portion of a drift ("room"), which is represented as a cylinder of $5.97 \mathrm{~m}$ radius and $3.05 \mathrm{~m}$ height. Throughout the period during which the drift remains open, of approximately 50 years, the pressure in the room is maintained at $\mathrm{p}=1 \mathrm{bar}$. The computational grid, shown in Figure 4, is identical to the "coarse mesh" used by Pruess and Bodvarsson (1982). Other problem specifications for the "room scale model" are given in Tables 1 and 2.

\section{Repository-Scale Model}

In this problem, the repository is idealized to be a flat circular disk with a given time-varying power density. The repository is assumed to be $1500 \mathrm{~m}$ in radius and situated in a fully saturated rock mass $900 \mathrm{~m}$ below the ground surface (Figure 5 ). The axisymmetric mesh used for numerical computation is shown in Figure 6. The top of the model is bounded by an isothermal impermeable surface $150 \mathrm{~m}$ below the ground level, at $10^{\circ} \mathrm{C}$ and corresponding hydrostatic pressure (1.62 MPa). The bottom surface is impermeable and at a $85^{\circ} \mathrm{C}$ corresponding to a $30^{\circ} \mathrm{C} / \mathrm{km}$ ambient geothermal gradient. 


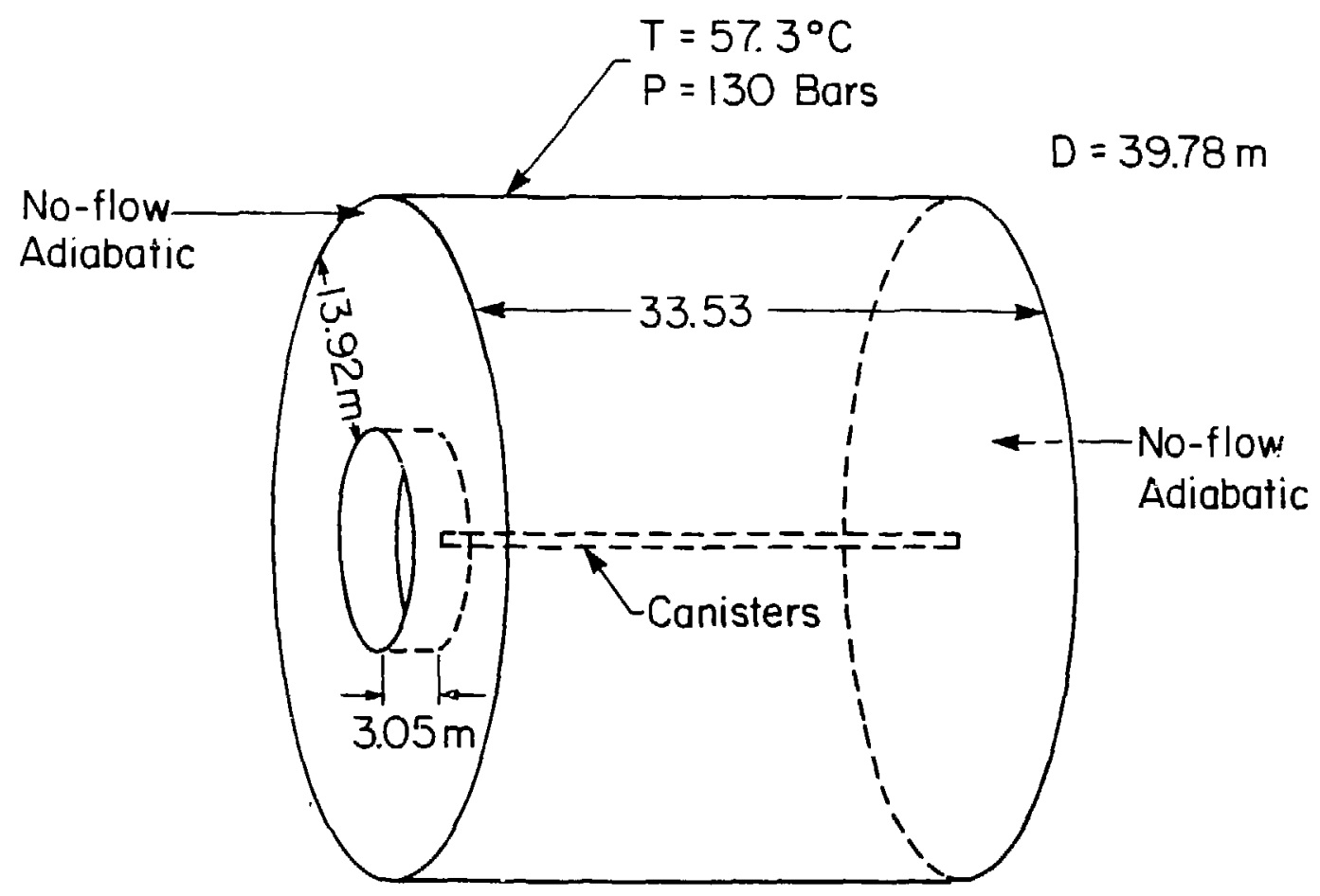

XBL 859-10771

Figure 3. Axisymmetric representation of the room-scale problem. 


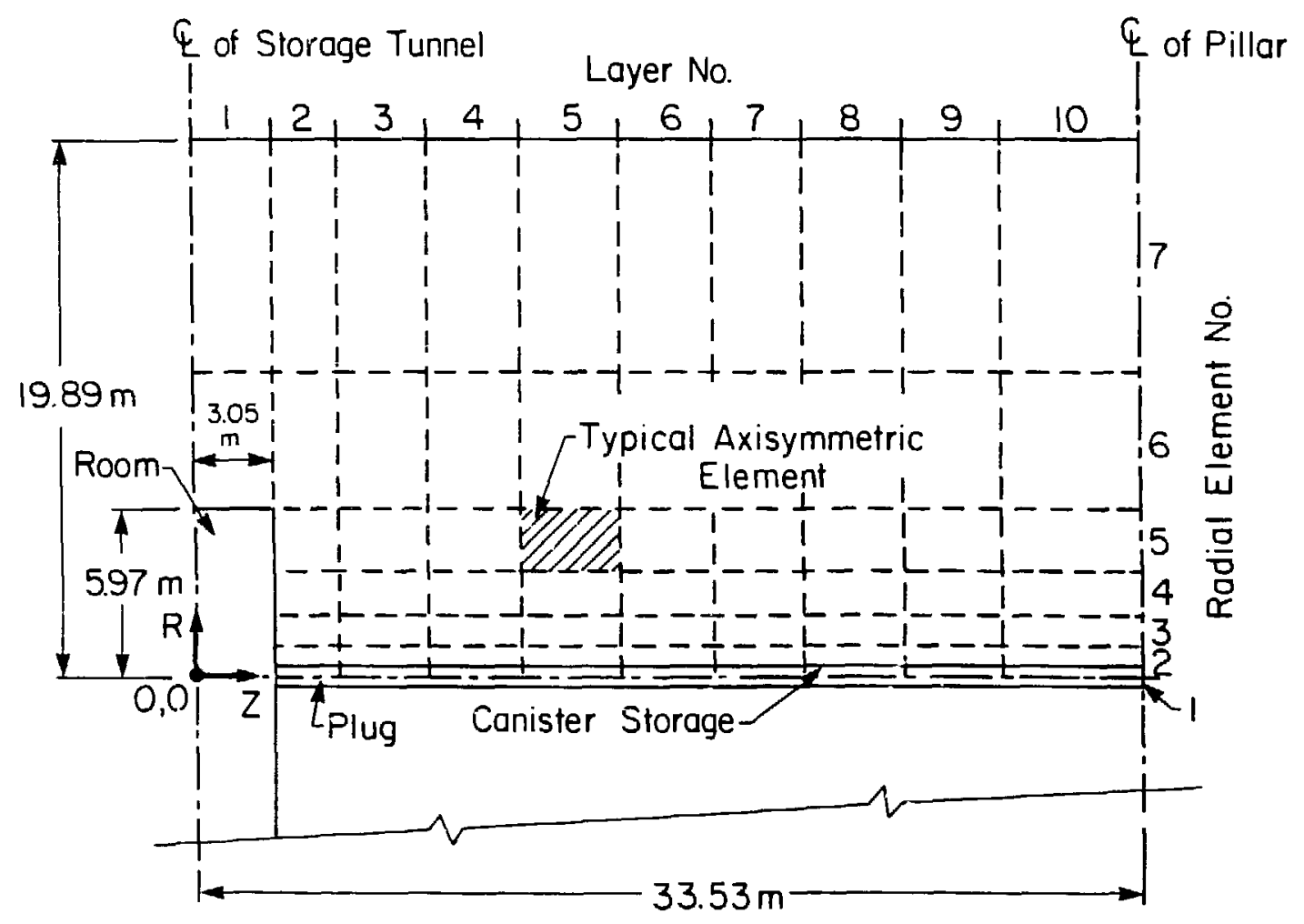

XBL 859-10769

Figure 4. Discretization of the room-scale problem. 
Table 1. Parameters used in room scale problem.

\begin{tabular}{|l|c|c|c|c|}
\hline \multicolumn{1}{|c|}{ Parameter } & Pillar & Plug & $\begin{array}{c}\text { Canister } \\
\text { Storage Hole }\end{array}$ & $\begin{array}{c}\text { Storage } \\
\text { Tunnel }\end{array}$ \\
\hline \hline Permeability $\left(\mathrm{m}^{2}\right)$ & $10^{-18}$ & $10^{-10}$ & $10^{-10}$ & $10^{-10}$ \\
Porosity & 0.001 & 0.50 & 0.769 & 0.50 \\
Sp. Heat $\left(\mathrm{J} / \mathrm{kg}^{\circ} \mathrm{C}\right)$ & 953.0 & 880.0 & 589.8 & 840.0 \\
Density $\left(\frac{\mathrm{kg}}{\mathrm{m}^{3}}\right)$ & 2780.0 & 2100.0 & 2895.0 & 2780.0 \\
Thermal & 2.3 & 2.192 & 2.3 & 50 \\
Cond. $\left(\frac{\mathrm{J}}{\mathrm{ms}^{\circ} \mathrm{C}}\right)$ & & & & \\
\hline
\end{tabular}


Table 2. Relative heat-generation rates of waste canisters.

\begin{tabular}{|c|c|}
\hline $\begin{array}{c}\text { Time After } \\
\text { Emplacement ( yrs. ) }\end{array}$ & Relative Heat-Generation Rate \\
\hline \hline 0 & 1.0 \\
5 & 0.849 \\
10 & 0.723 \\
15 & 0.621 \\
20 & 0.539 \\
30 & 0.424 \\
40 & 0.361 \\
50 & 0.330 \\
70 & 0.285 \\
\hline
\end{tabular}




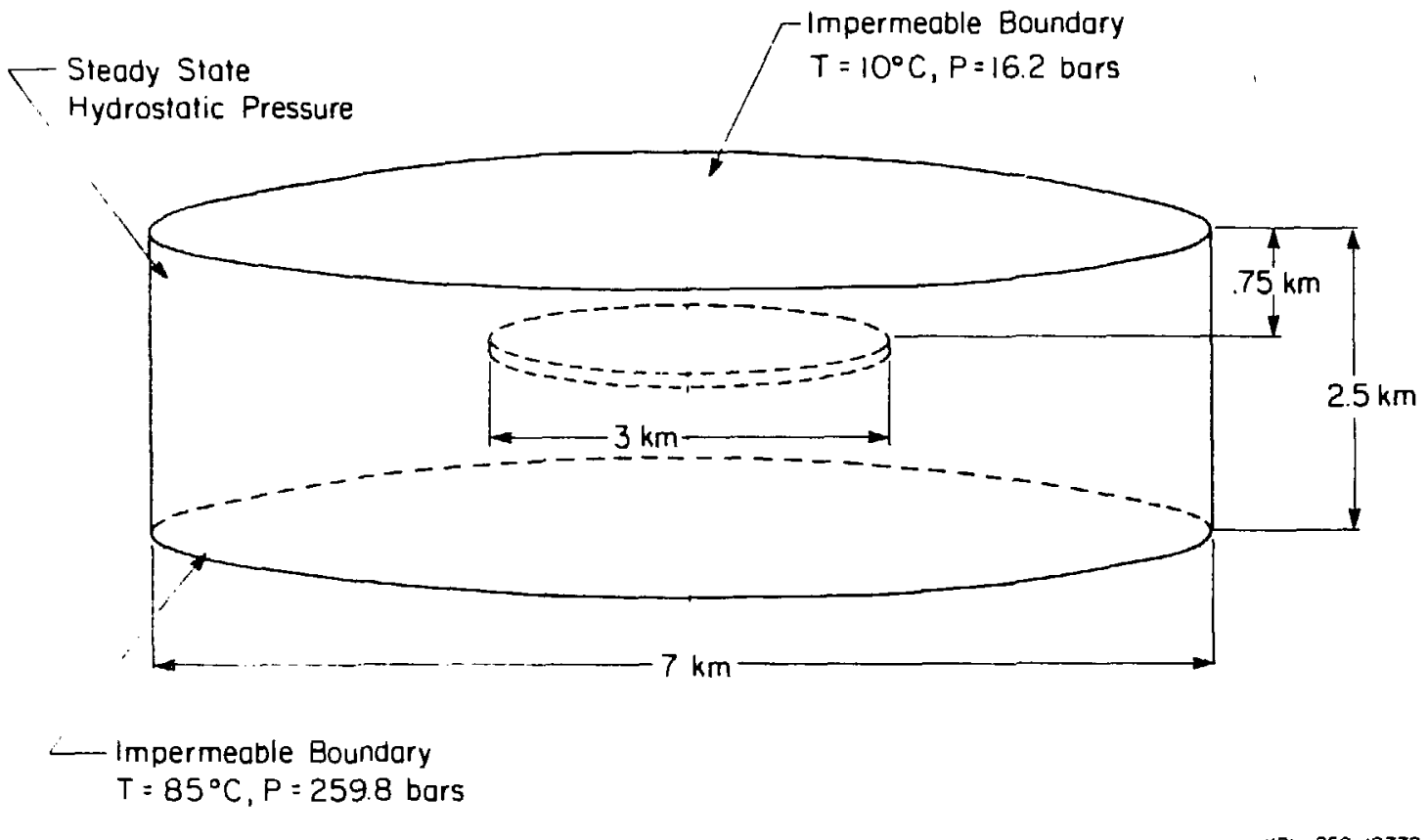

X日L 859.10772

Figure 5. Schematic of the .xisymmetric model of the repository. 


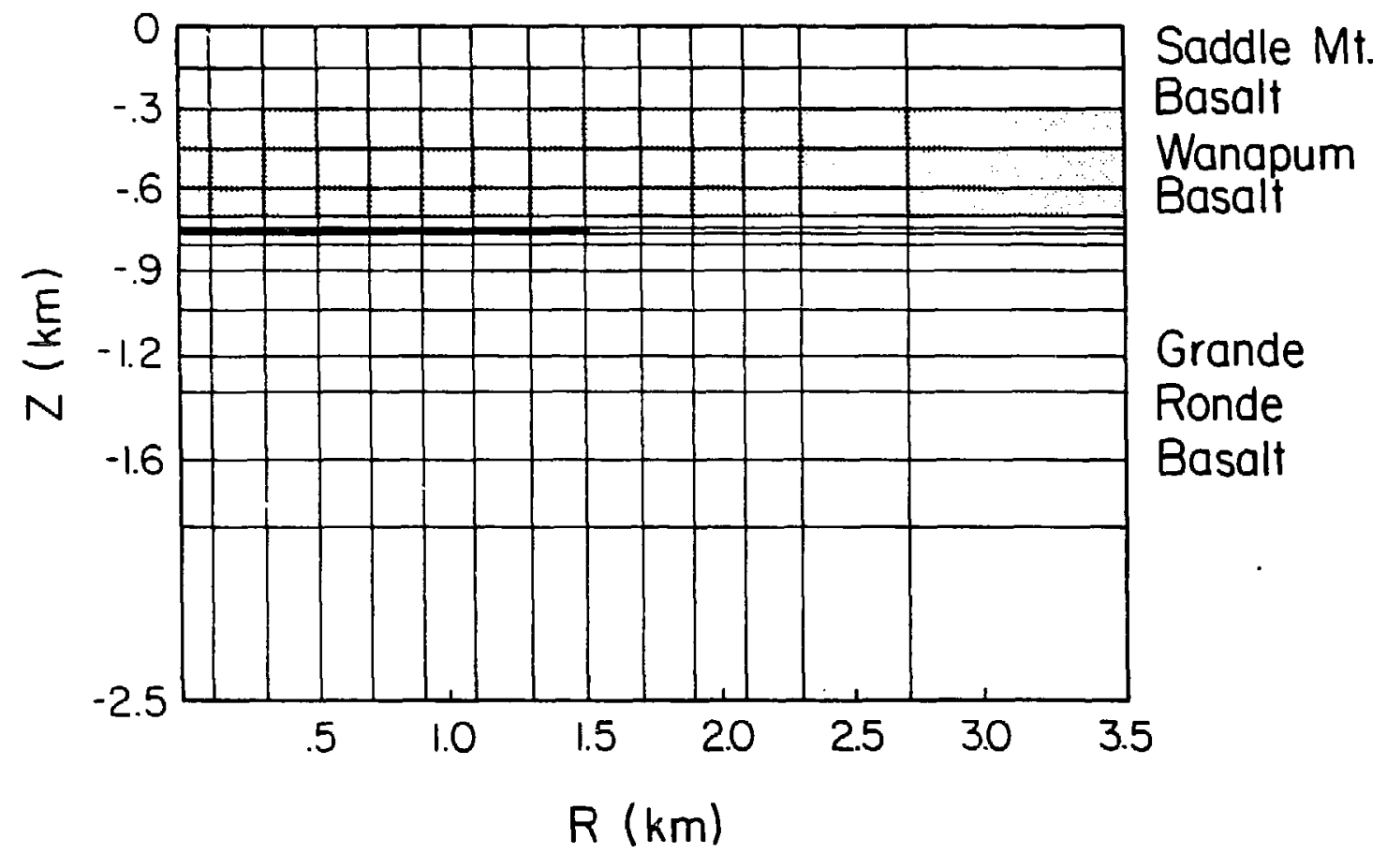

XBL 859-10770

Figure 6. Discretization of the axisymmetric repository model. 
The lateral boundary is maintained at steady state pressure and temperature corresponding to ambient hydrostatic pressure gradient and ambient geothermal gradient, respectively. Regional flow is ignored.

In order to reduce the numerical effort, it is assumed that the entire repository is instantaneously loaded and filled to an areal power density of $22 \mathrm{~W} / \mathrm{m}^{2}$. The effects of the pressure sink related to the storage tunnel are also ignored because resaturation is expected to take place within a short time $(\sim 100$ years $)$ compared to the time period of regional fluid movement $(\sim 10,000$ years $)$ considered in this study.

The repository parameters used in the present study are presented in Table 3 . Although the current study was not intended to provide a site-specific analysis, we have employed formation properties suggested for the BWIP site in Hanford (DOE Report, 1982). No distinction is made between the waste canister, backfilled material, and the repository host rock. The power density is assumed to decline with time, corresponding to that of spent fuel (Figure 7). 
Table 3. Repository site parameters used in repository-wide scale model.

\begin{tabular}{|l|c|c|c|}
\hline \multicolumn{1}{|c|}{ Parameter } & Saddle Mt. & Wanapum & Grande Ronde \\
\hline \hline Horiz. Permeability $\left(\mathrm{m}^{2}\right)$ & $10^{-15}$ & $3 \times 10^{-16}$ & $10^{-16}$ \\
Vert. Permeability $\left(\mathrm{m}^{2}\right)$ & $10^{-17}$ & $3 \times 10^{-18}$ & $10^{-18}$ \\
Porosity & 0.002 & 0.001 & 0.001 \\
Thermal Cond. $\left(\frac{\mathrm{J}}{\mathrm{ms}^{\circ} \mathrm{C}}\right)$ & 2.3 & 2.3 & 2.3 \\
Density $\left(\frac{\mathrm{kg}}{\mathrm{m}^{3}}\right)$ & 2800. & 2800. & 2800. \\
Heat Capacity $\left(\frac{\mathrm{J}}{\mathrm{kg}^{\circ} \mathrm{C}}\right)$ & 950. & 950. & 950. \\
\hline
\end{tabular}




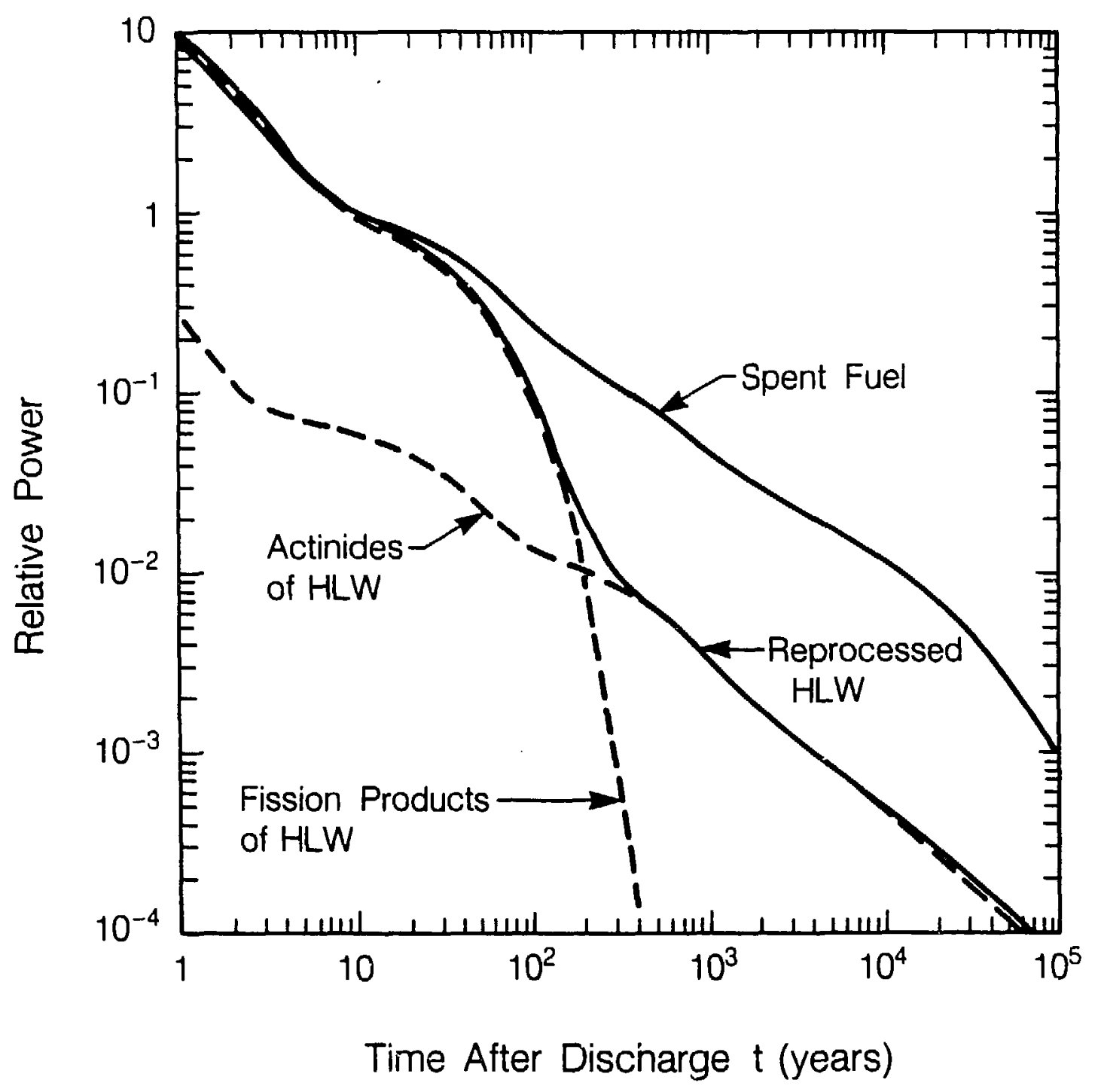

XBL 8512-12692

Figure 7. Decay of the power density with time. 


\section{RESULTS}

The results of this study are presented in two parts, one for the room-scale model and another for the repository-scale model. Since the physical phenomena pertaining to the performance assessment of a nuclear waste repository are different at these two scales, a qualitative description of the phenomenology is given before the numerical results. This will facilitate presentation of the results and clarify the approach used in the simulation.

\section{Room-Scale Model}

\section{General Phenomenology}

The case studied by Pruess an Bodvarsson (1982) without inclusion of silica redistribution will be referred to as "refer?nce case". We quote Pruess and Bodvarsson (1982) for description of the reference case before discussing the results of silica redistribution:

"It is assumed that the waste packages are emplaced "hot"; at a temperature of $300^{\circ} \mathrm{C}$. In low permeability rocks, most of the heat generated by the canisters is removed by thermal conduction. After emplacement in a relatively cool $\left(54^{\circ} \mathrm{C}\right)$ host rock, canister temperatures initially decline, but, within a few days, heat loss to the rock decreases to a level below the rate of heat generation in the canisters. Subsequently, both temperatures and temperature gradients increase everywhere in the system, with the largest increases occurring in the immediate vicinity of the canister storage hole. About two years after emplacement, temperature gradients have increased to the point where all generated heat is being removed from the canisters. This causes canister temperatures to first stabilize, and then to slowly decline as heat output diminishes. At greater distance from the canister storage hole, temperatures remain lower, 
and maximum temperatures are reached somewhat later.

Prior to backfilling, canister storage holes and storage roms are close to atmospheric pressure ( 1 bar), while groundwater pressure at the depth of the reference horizon is approximately 130 bars $(13 \mathrm{MPa})$. This causes pore fluids to migrate toward the pressure sink (canister holes and storage rooms). Due to the small compressibility of liquid water, the pressure pulse diffuses rapidly outward, away from storage rooms and canister holes, and reaches the boundaries of the low-permeability zone in a matter of days. Subsequently, a quasi-steady flow field is maintained throughout the open period of the repository, with water influx at the boundary of the low permeability zone closely matching discharge in to the excavations."

As water flows towards the excavations, temperature and silica solubility generally increase. Therefore, the water flowing into a pore space is always deficient in silica with respect to the local solubility, and local equilibrium is achieved by dissolution of silica from the rock mas3. Dissolution of silica results in an increase in flow rate because of the enhanced formation permeability. However, this flow increase causes secondary effects which tend to diminish these changes: an increased flow rate tends to reduce the temperature along the flow path, thus diminishing the fluid mobility because of higher fluid viscosity at lower temperatures.

When the permeability enhancements are very large near the canister holes, a low pressure front propagates rapidly into the rock surrounding the canister holes. If the pressure drops below the saturation pressure, boiling occurs and the resulting two-phase zone acts as an additional barrier to the flowing fluid because of relative permeability effects. 


\section{Thermal and Hydrologic Effects}

For the reference case and the new cases studied with inclusion of silica redistribution, the computed total fuid flow in to the storage room and the canister hole essentially equals the total fluid flow at the boundary of the model. This indicates that quasi-steady flow conditions are present at all times due to the low fluid compressibility, and the slow rates of change in the temperature field. The changes in total flow rate with time for all four models are illustrated in Figure 8 . The figure indicates that for the reference case the flux initially increases due to reduced viscosity of the heated fluid. Later, as the thermal output from the canisters decreases, the rock and fluid temperatures decrease and the flow diminishes. The figure also indicates that redistribution of silica enhances the total fluid flow rates by up to $30 \%$ with respect to the reference case.

Figure 9 illustrates the temperature history at two different locations in the rock mass for the reference case and the series model with $\phi_{\mathrm{c}}=0.95$. The results of the other two studies fall within these limits, with the cubic case being closer to the reference case and the series model with $\phi_{\mathrm{c}}=0.8$ being closer to the series model wath $\phi_{\mathrm{c}}=0.95$. A similar trend was found in the temperature profiles at 10 and 30 years after emplacement (Figure 10). These two figures illustrate that redistribution of silica causes the rock temperature to reduce everywhere at all times. However, the differences are generally small ( $\leq 10^{\circ} \mathrm{C}$ over most of the flow system).

Upon reexamining Figure 8 one can conclude that silica redistribution brings about two counteracting phenomena affecting the fluid flow: the formation perméability is increased and the fluid mobilities are decreased with respect to the reference case. The net result is an enhancement of flow because the former effect is dominant.

An inflection in the flow rate for the series model with $\phi_{\mathrm{c}}=0.95$ at approximately 28 years is caused by boiling in the rock mass (see Fig. 8). The presence of two-phase conditions presents a larger flow resistance due to relative permeability effects. After 


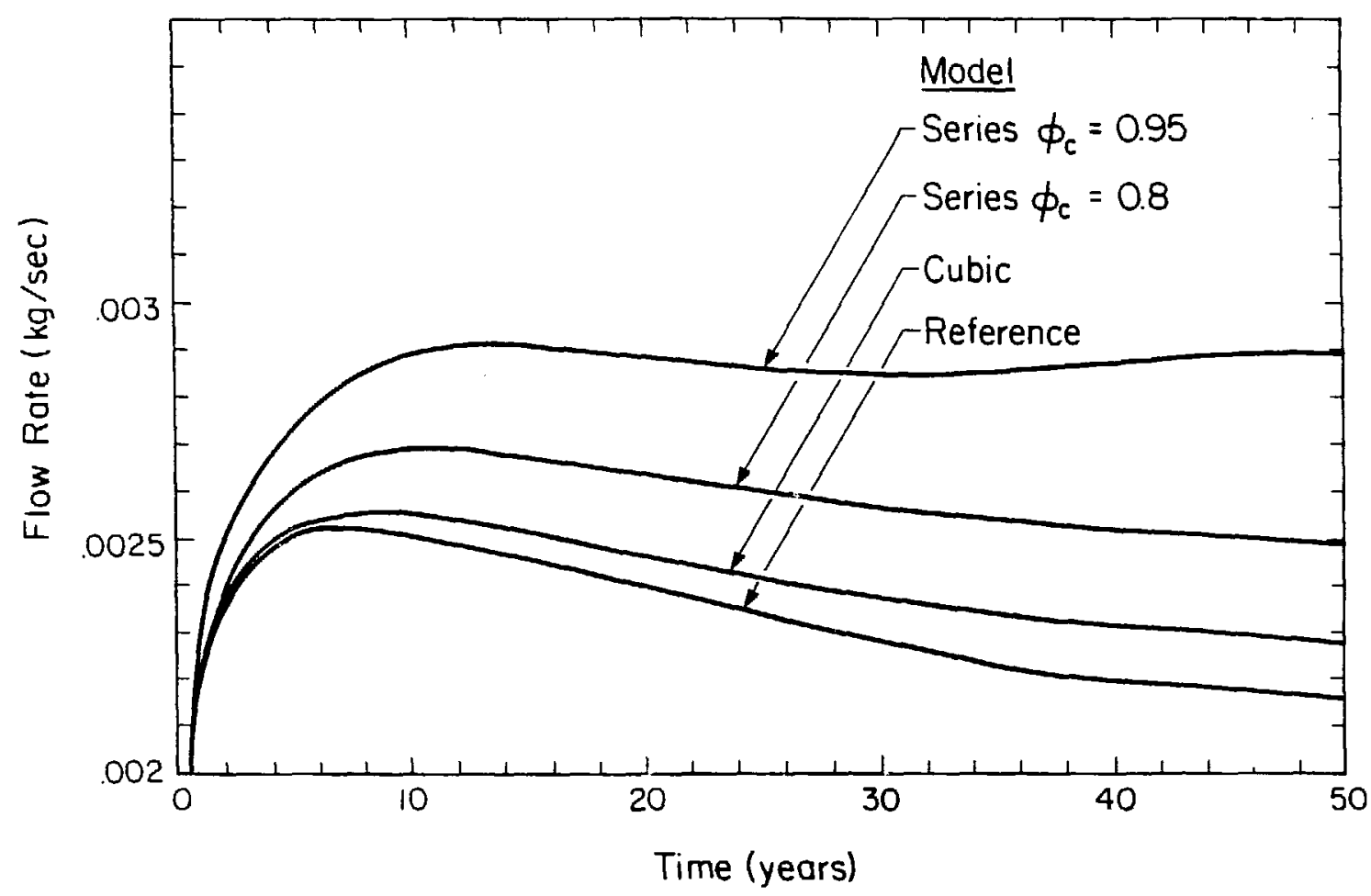

XEL $859-10765$

Figure 8. History of total fluid flow rates in to the canister holes and storage room for room-scale problem. 


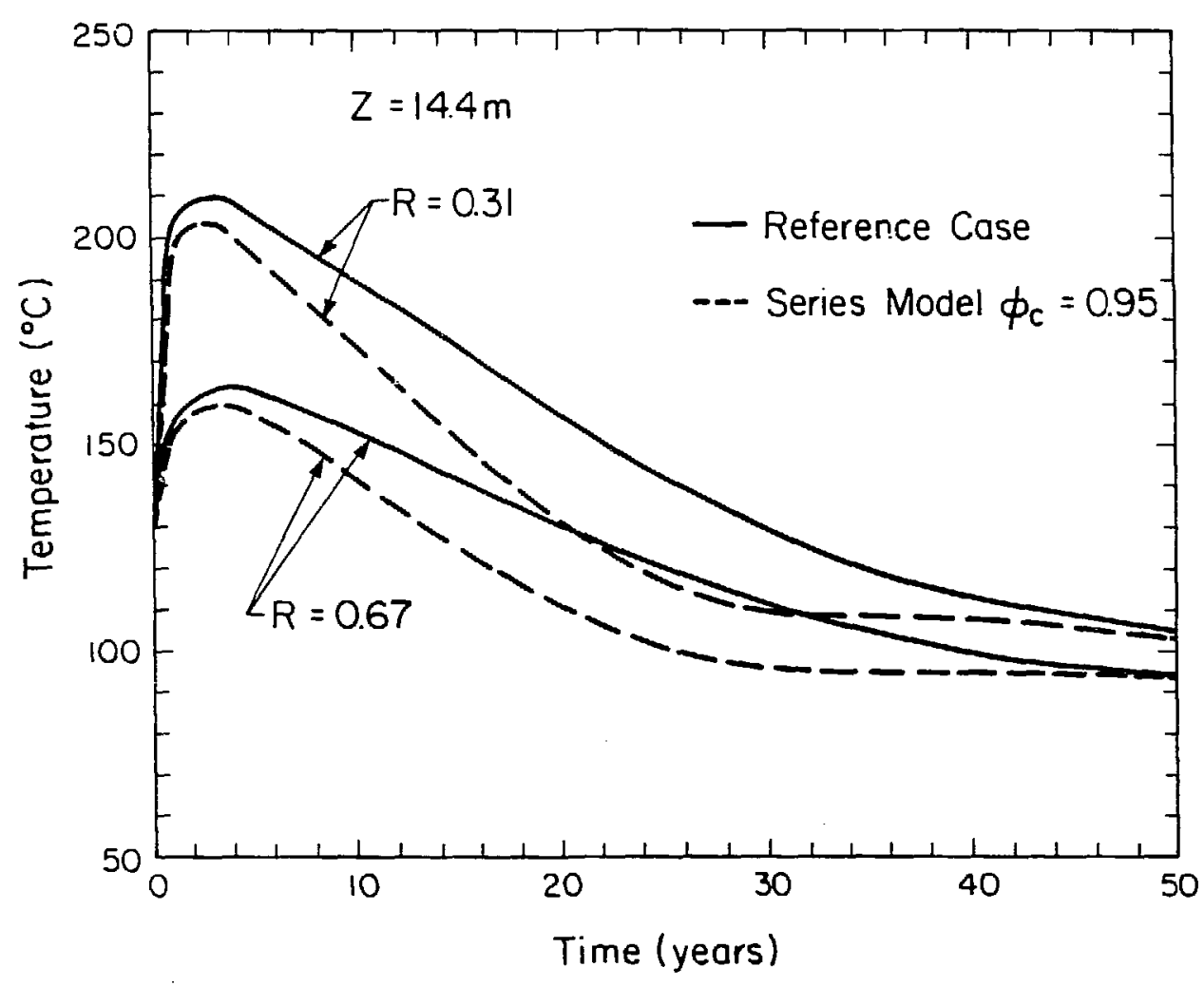

XEL 859-10768

Figure 9. Variations in temperature at diferent locations in room scale problem with and without inclusion of silica redistribution effects. 


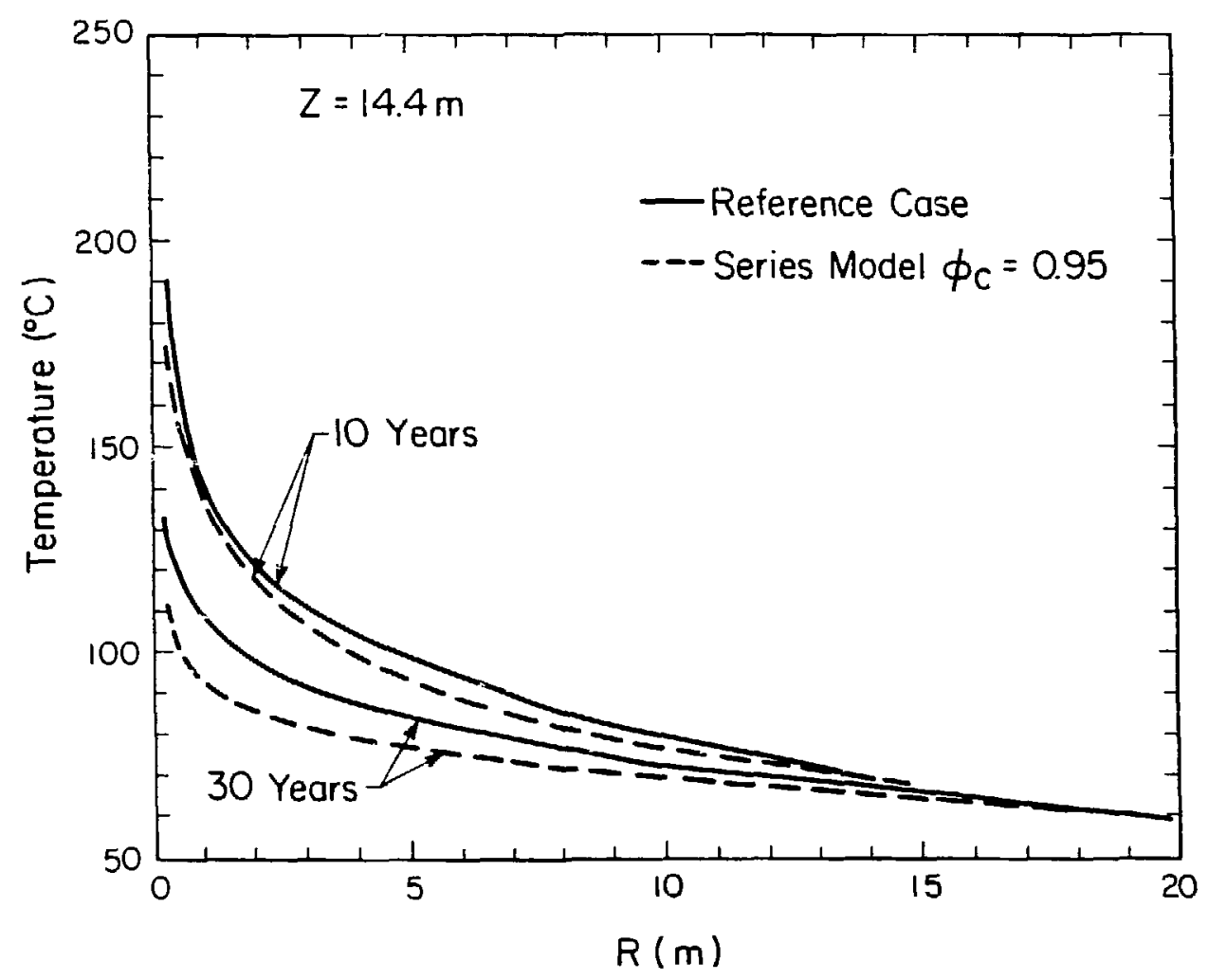

XEL 859-10767

Figure 10. Temperature profiles at different times in room scale problem with and without inclusion of silica redistribution effects. 
disappearance of the steam phase at approximately 28 years, the flow rate rises again and reaches a plateau at approximately 44 years.

Porosity enhancement for the series model with $\phi_{c}=0.8$ at two different times is presented in Figure 11. The results of the two other models fall within 0.008 of this curve. This observation at first seems counterintuitive in light of large flow-rate differences among the three models considered in this study. But the observation seems plausible when one considers the fact that higher flow rates result in lower temperature rise and temperature gradients.

\section{Boiling in the Rock Mass}

It was found in a previous study (Pruess and Bodvarsson, 1982) that a very fine :spatial resolution is required near the canister hole in order to predict the exact (very small) extent of the boiling (two-phase) zones. However, because of the high cost of numerical computation when using a "fine mesh," only a "coarse mesh" calculation was carrad out here (see Figure 4), so that the extent of the boiling zone is underestimated in this study.

It is because of this reason that no boiling was observed in the reference case, the cubic model, and the series model with $\phi_{\mathrm{c}}=0.8$. But, steam phase appears in the first ring of rock elements surrounding the canister hole for a series model with $\phi_{c}=0.95$ (actual extent of boiling is probably larger). One may therefore conclude that the extent of boiling in the cubic model and the series model with $\phi_{\mathrm{c}}=0.8$ is intermediate between the boiling zones observed by Pruess and Bodvarsson (1982) in their "fine mesh" simulation of the reference case without silica redistribution effects, and the series model with $\phi_{\mathrm{c}}=0.95$

The "fine mesh" calculations of the reference case (Pruess and Bodvarsson, 1982) show that the maximum rock volume in which boiling occurs is $0.46 \mathrm{~m}^{3}$ per canister. This value is reached 10 months after emplacement, at which time boiling extends to a 


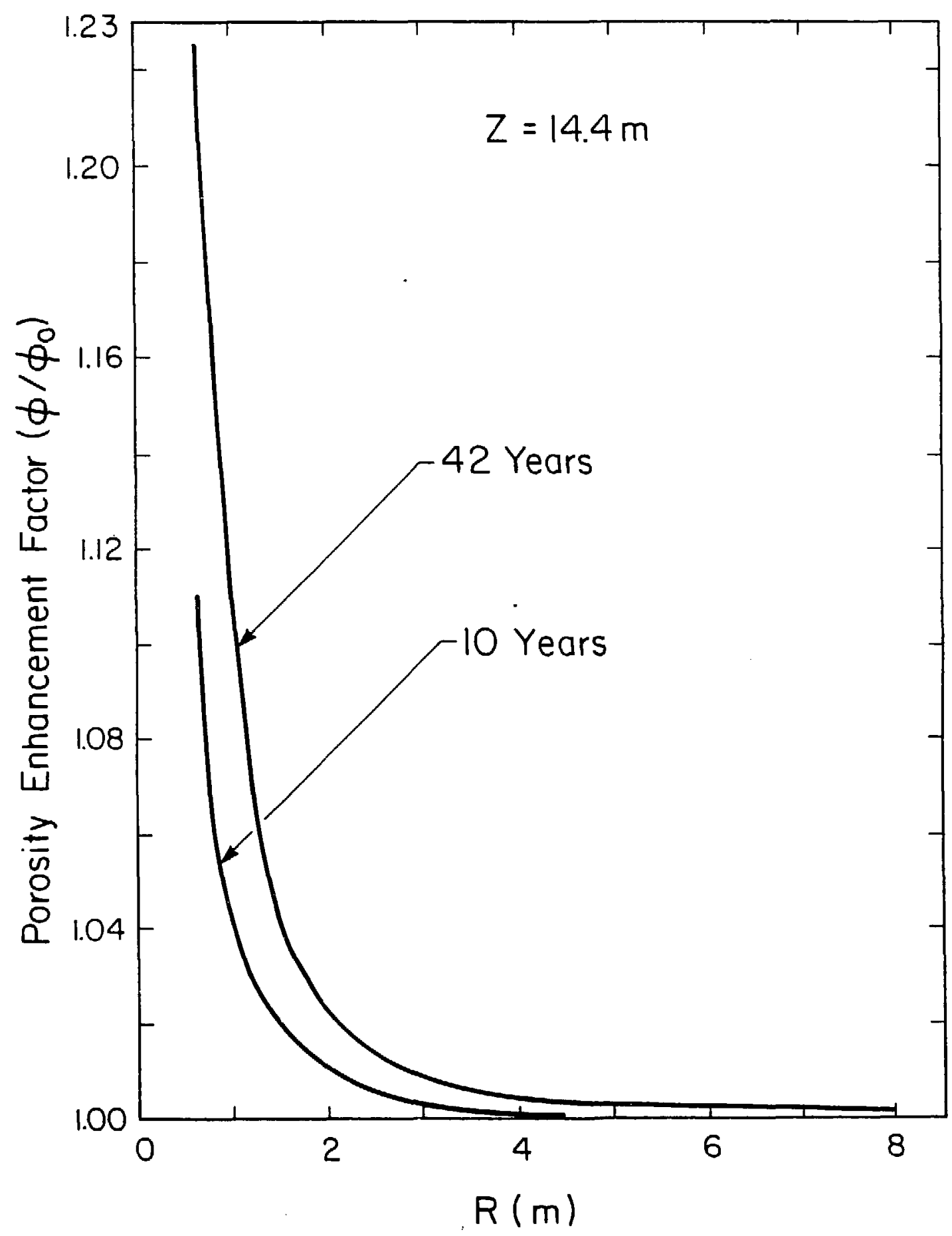

XBL $859-10766$

Figure 11. Porosity enhancement at 10 and 42 years in room scale model $\left(\phi_{0}=0.8\right)$. 
radial distance of $13.2 \mathrm{~cm}$ beyond the wall of the canister hole. The rock mass thus desaturated is resaturated in 44 years, before the assumed backfilling and decommisioning of the repository.

Table 4 compares the extent of boiling in the reference case and the series model with $\phi_{c}=0.95$. From the table we can see that silica redistribution effects tend to enlarge the two-phase zone, and to reduce the resaturation time. These changes are brought about because dissolution of silica enhances the permeability primarily near the canister hole, and therefore causes low pressures (and boiling) to advance further in to the rock mass. Enhanced permeability also causes faster resaturation, because of overall increased fluid flow and cooling rates.

\section{Repository-Scale Model}

\section{General Phenomenology}

It is assumed that the entire repository is loaded at once and that there are no pressure sinks within the repository. Since a repository is expected to receive waste over a few decades and resaturation is expected to take place within 100 years, the impact of the above-mentioned assumptions on a simulation study for up to 10,000 years is expected to be negligible. Heating of the repository and its surroundings due to radioactive decay of the waste causes a natural convection cell to develop in which flow is driven by the buoyancy force of the heated water relative to the surrounding colder water. In this convection cell, water moving towards the repository generally moves towards higher temperatures, thus dissolving silica along its flow path. Upon leaving the repository, the point of maximum temperature, the silica enriched water moves towards regions of lower temperature and solubility, and precipitation of silica along the flow channel takes place. This phenomenon will, in general, result in an overall increase in flow resistance in a medium with homogeneous permeability. 
Table 4. Extent of boiling and resaturation times with and without inclusion of silica redistribution effects.

\begin{tabular}{|c|c|c|c|}
\hline & $\begin{array}{l}\text { Boiling vol./ } \\
\text { canisters }\left(\mathrm{m}^{3}\right)\end{array}$ & $\begin{array}{l}\text { Radial extent } \\
\text { of boiling }(\mathrm{m})\end{array}$ & $\begin{array}{l}\text { Resaturation } \\
\text { time (years) }\end{array}$ \\
\hline $\begin{array}{l}\text { Reference } \\
\text { Case }\end{array}$ & 0.46 & 0.132 & 44 \\
\hline $\begin{array}{l}\text { Series model } \\
\dot{\phi}_{c}=0.95\end{array}$ & $\geq 9.2$ & $\geq 0.67$ & 28 \\
\hline
\end{tabular}


Porosity and permeability changes are not only brought about by silica redistribution on a macroscopic scale, but also by local changes in solubility due to changing temperatures. When the temperatures in the repository and the host rock rise due to waste emplacement, silica from the flow channel walls dissolves resulting in increased rock porosity and permeability. When the temperature declines these effects are reversed.

\section{Flow and Temperature Field}

Figure 12 displays the temperature vs. depth profile along the axis of the repository for the reference case (no silica), at different times after waste emplacement. The initial undisturbed temperature profile is a straight line, representing a normal geothermal gradient of $30^{\circ} \mathrm{C} / \mathrm{km}$. At early times the temperature rise is localized near the repository horizon. After approximately 1000 years, heat from the repository reaches the top of the formation and begins to leak out. Radially, the temperature is fairly uniform within the radius of the repository, beyond which the temperature drops sharply. The effects of silica redistribution on these temperature profiles are so small that a plot will fall within a line's width of the reference plot.

A comparison of the temperature histories of the repository center for the reference case and the series model with $\phi_{c}=0.95$ is given in Figure 13. It shows that silica redistribution results in somewhat lower repository temperature, but the differences are $\leq 7^{\circ} \mathrm{C}$ at all times, which is not significant. Redistribution of silica also has an insignificant effect on the vertical flow velocities (Table 5). The results indicate that at early times $(\sim 100$ years) redistribution causes a reduction in flow. However, at later times $(\geq 500$ years) the effects are reversed because the local dissolution dominates over the changes brought about by non-isothermal flow. 


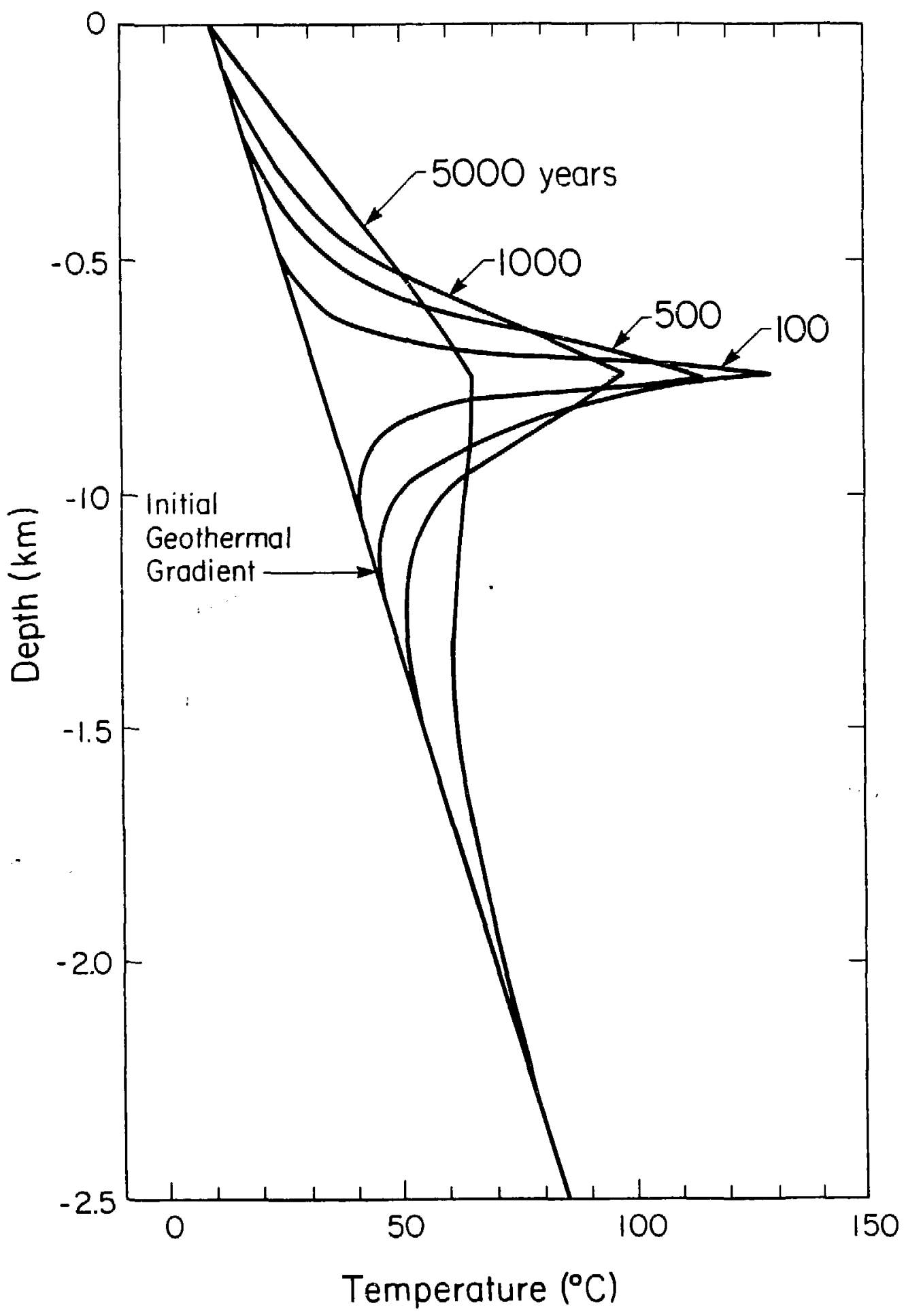

XBL 859-10762

Figure 12. Vertical temperature profiles along the repository axis. 


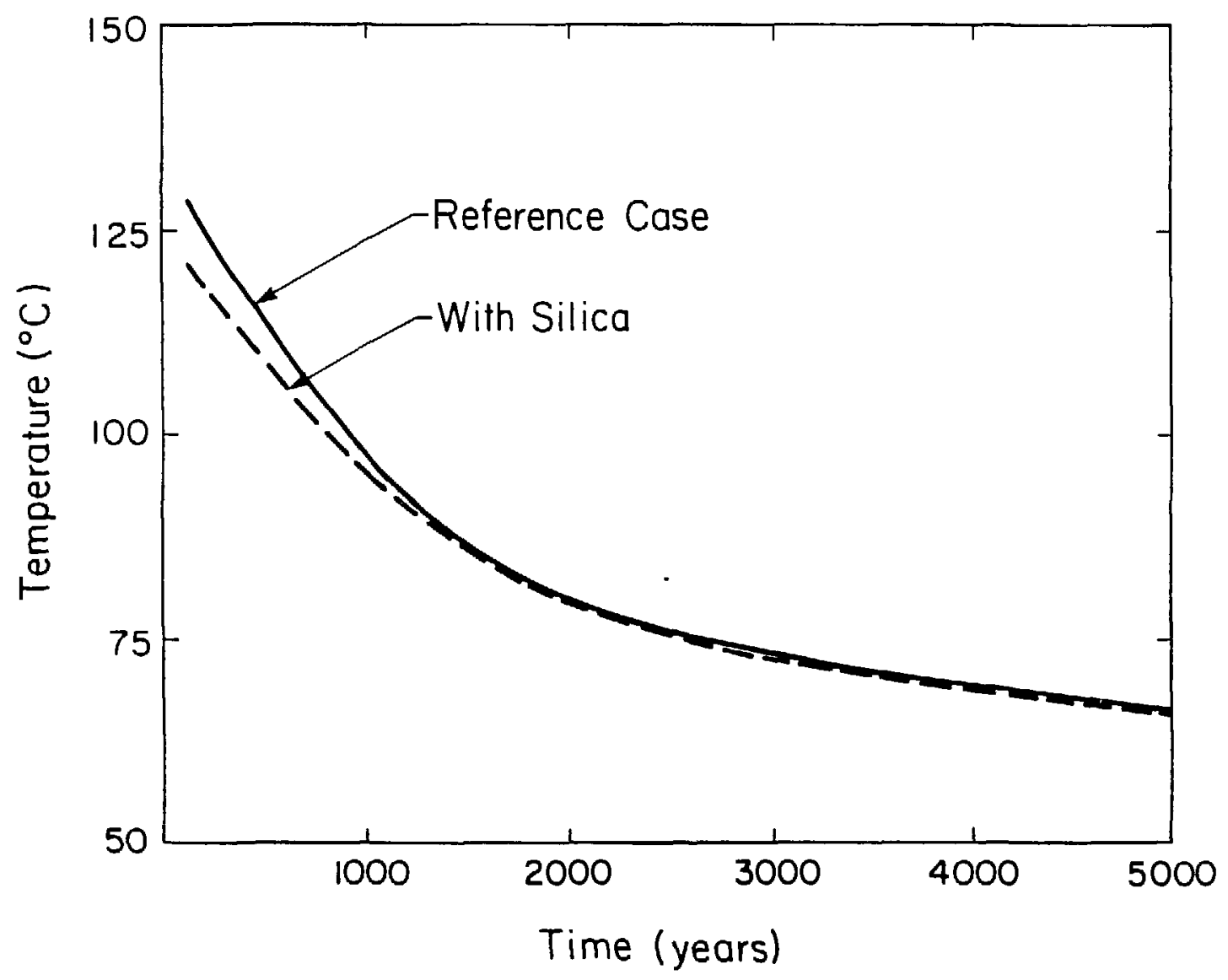

XBL $859-10763$

Figure 13. The effects of silica redistribution on the temperature history of the repository center. ("series" model with $\phi_{c}=0.95$ ). 
Table 5. Vertical flow velocity through the repository axis with and without inclusion of silica redistribution effects.

\begin{tabular}{|c|c|c|c|c|}
\hline \multirow{2}{*}{ Cases } & \multicolumn{4}{|c|}{ Vertical Velocity $\left(\mathrm{x} 10^{-10} \mathrm{~m} / \mathrm{sec}\right)$ at Times (years) } \\
\cline { 2 - 5 } & 100 & 500 & 1000 & 5000 \\
\hline \hline Reference & 2.97 & 4.33 & 3.87 & 1.81 \\
\hline $\begin{array}{c}\text { Series Model } \\
\phi_{\mathrm{c}}=0.95\end{array}$ & 2.92 & 4.36 & 4.00 & 1.86 \\
\hline
\end{tabular}




\section{CONCLUSIONS}

We have studied effects of silica redistribution in thermally driven flow fields near high-level nuclear wastes emplaced in saturated rocks, both on a room scale and a repository-wide scale. Our studies are not necessarily indicative in a quantitative sense of the effects to be expected at the various potential repository sites currently under consideration. However, we believe that some general conclusions can be drawn.

Silica redistribution will tend to increase effective formation permeability and fluid migration velocities, while diminishing formation temperatures near the canister holes. None of these effects appear to be significant and of any concern, especially when viewed against general uncertainties in applicable formation parameters at any specific site. For example, changes in predicted temperatures from silica redistribution effects are generally below $10^{\circ} \mathrm{C}$ everywhere except in the immediate vicinity of the waste packages, where somewhat larger effects appear possible. These conclusions were arrived at on the basis of conservative assumptions, which tend to overpredict thermohydrological effects of silica redistribution. Specifically we mention the assumption of instantaneous local equilibrium for dissolved silica concentrations, and the very severe porosity-permeability relationship used here which accounts for permeability effects of pore-throats and bottle necks in flow channels.

From the viewpoint of assessing thermohydrological conditions, and migration of dissolved species near a high-level nuclear waste repository in saturated rock, our results suggest that effects of silica redistribution may be safely ignored. However, near nuclear waste packages emplaced in partially saturated media conditions may be different. It is possible that "heat pipe" conditions with persistent liquid-vapor counterflow may evolve (Pruess and Wang, 1984), which could cause substantial amounts of mineral redistribution in the near-canister region. 


\section{ACKNOWLEDGEMENT}

The authors would like to thank Dr. Marcelo Lippmann for reviewing the manuscript and suggesting improvements. 


\section{NOMENCLATURE}

b fracture aperture

C specific heat

k intrinsic permeability

$F^{(i)} \quad$ mass flux of component $i$

$\mathrm{M}^{(i)} \quad$ accumulation term of component $\mathrm{i}$

n unit normal vector

$Q^{(i)} \quad$ source term for component $i$

S saturation

t time

T absolute temperature

u specific internal energy

$\mathrm{X}$ mass fraction of silica

V volume

\section{Greek Symbols}

$\Gamma \quad$ fractional length (Fig. 1)

$\theta \quad$ normalized porosity

$\nu \quad$ area ratio for fracture $(=\bar{b} / \mathrm{b})$

$\rho$ density

$\tilde{\phi} \quad$ gross porosity

$\sigma \quad$ area of element

$\phi \quad$ porosity $\left(\phi=\tilde{\phi}\left(1-\mathrm{S}_{\mathrm{s}}\right)\right)$

\section{Subscripts and Superseripts}

c critical values

$i \quad$ index of mineral component

$l \quad$ liquid phase 
grid block number

o initial condition

r

formation rock

$\mathbf{s}$

solid phase silica

v

vapor phase 


\section{REFERENCES}

Braithwaite, J. W., and Nimick, F. B., Effect of Host-Rock Dissolution and Precipitation on Permeability in a Nuclear Waste Repository in Tuff, Sandia Report SAND840192, Sandia National Laboratories, Albuquerque, New Mexico, September 1984.

DOE Report, Site Characterization Report for Basalt Waste Isolation Froject at Hanford, Report No. DOE/R L 82-3, prepared by Rockwell, Hanford Operations, Hanford, WA., 1982.

Duff, I. S., MA28 - A Set of FORTRAN Subroutines for Sparse Unsymmetric Linear Equations, Report No. AERE-R-8730, Computer Sciences and Systems Division, AERE Harwell, Oxfordshire, U.K., July 1977.

Fournier, R. O., and Potter, R. W., An Equation Correlating the Solubility of Quartz in Water from $25^{\circ} \mathrm{C}$ to $900^{\circ} \mathrm{C}$ at Pressures Up to 10,000 Bars, Geochimica et Cosmochimica Acta, vol. 56, pp. 1969-1973, 1982.

Haar, L., Gallagher, J., and Kell, G. S., Thermodynamic Properties for Fluid Water, Proceedings, 9th International Conference on Properties of Steam, pp. 1-14, Munich, 1979.

International Formulation Committee, A Formulation of the Thermodynamic Properties of Ordinary Water Substance, IFC Secretariat, Duesseldorf, Germany, 1967.

Keith, L. A., Delaney, P. T., and Moore, D. E., Permeability Reduction Due to Precipitation of Quartz under Nonisothermal Conditions, Proceedings, Ninth Workshop on Geothermal Reservoir Engineering, Stanford University, Stanford, CA, December 1983.

Moore, D. E., Morrow, C. A., and Byerlee, J. D., Si0. Precipitation Accompanying Fluid Flow Through Granite Held in a Temperature Gradient, Proceedings, Seventh Workshop on Geothermal Reservoir Engineering, Stanford University, Stanford, CA, December 1981. 
Morrow, C., Lockner, D., Moore, D., and Byerlee, J., Permeability of Granite in a Temperature Gradient, Journal of Geophysical Research, Vol. 86, No. 84, pp. 30022008, April 1981.

Pruess, K., Development of the General Purpose Simulator MULKOM, Annual Report, 1982, Earth Sciences Division, Lawrence Berkeley Laboratory, Berkeley, CA, 1983.

Pruess, K., and Bodvarsson, G. S., Hydrothermal Conditions and Resaturation Times in Underground Openings for a Nuclear Waste Repository in the Umtanum Flow at the Basalt Waste Isolation Project, Lawrence Berkeley Laboratory Report No. LBL-18451, Berkeley, California, July 1982.

Pruess, K., and Narasimhan, T. N., A Practical Method for Modeling Fluid and Heat Flow in Fractured Porous Media, Society of Petroleum Engineers Journal, Vol. 25, No. 1, pp. 14-26, February 1985.

Pruess, K., and Wang, J. S. Y., TOUGH - A Numerical Model for Nonisothermal Unsaturated Flcw to Study Waste Canister Heating Effects, in: G. L. McVay (ed.), Mat. Res. Soc. Symp. Proc., Vol. 26, Scientific Basis for Nuclear Waste Management, pp. 1031-1038, North Holland, New York, 1984.

Vaughan, P. J., Analysis of Permeability Reduction During Flow of Heated, Aqueous Fluid through Westerly Granite, paper presented at Int. Symp. on Coupled Processes Affecting the Performance of a Nuclear Waste Repository, Berkeley, CA, September 18-20, 1985.

Verma, A. K., and Pruess, K., Effects of Silica Redistribution on Thermo-Hydrologic Conditions near High-Level Nuclear Waste Repositories in Saturated Geologic Formations, Lawrence Berkeley Laboratory Report No. LBL-20479, Berkeley, California, 1986. 
This report was done with support from the Department of Energy. Any conclusions or opinions expressed in this report represent solely those of the author(s) and not necessarily those of The Regents of the University of California, the Lawrence Berkeley Laboratory or the Department of Energy.

Reference to a company or product name does not imply approval or recommendation of the product by the University of California or the U.S. Department of Energy to the exclusion of others that may be suitable. 